
\title{
3 Research Square \\ Proanthocyanidins Induce miR-133b Expression to Promote Ischemic Skeletal Muscle Regeneration by Targeting MKP1
}

\section{Shi Chen}

Southwest Medical University https://orcid.org/0000-0002-9103-3785

Chao Du

Southwest Medical University

Lilong Pan

Jiangnan University

Qian Yang

Chengdu Medical College

Peihe Yu

Southwest Medical University

Fei Wu

Southwest Medical University

Yang Zhou

Southwest Medical University

Rui Hai

Southwest Medical University

Chunxiang Zhang

Southwest Medical University

Xiangyu Zhou ( $\square$ xiangyuzhou971@vip.126.com )

Affiliated Hospital of Southwest Medical University https://orcid.org/0000-0001-8976-9489

\section{Research}

Keywords: Proanthocyanidins, peripheral arterial disease, skeletal muscle regeneration, satellite cells, miR-133b, MKP1

Posted Date: August 28th, 2020

DOI: https://doi.org/10.21203/rs.3.rs-63522/v1

License: (c) (1) This work is licensed under a Creative Commons Attribution 4.0 International License.

Read Full License 


\section{Abstract}

Background: Limb ischemic necrosis is mainly attributed to peripheral arterial disease (PAD). Reducing oxidative stress and promoting damaged skeletal muscle regeneration may be benefit for ischemic limb treatment. Proanthocyanidins (PC) is a powerful antioxidant and free radical scavenger, but little is known about its role and related molecular mechanism in limb ischemic injury. The current study was undertaken to explore its role in the damaged skeletal muscle regeneration both in vitro and vivo, and whether MicroRNAs (miRNAs) involved in this process.

Methods: The potential effects of PC on the damaged muscle regeneration were explored in human skeletal muscle satellite cells (HSKMSCs) under hypoxic-ischemic condition and in mice limb ischemia model, then, aberrant expression of miRNAs in ischemic skeletal muscles were determined by microarray analysis, and regulatory mechanism of the specific miRNA on HSKMSCs myogenic differentiation was further investigated by gain and loss of functional experiments. Additionally, the direct target gene was examined by luciferase reporter assay.

Results: In mice limb ischemia model, our results revealed that PC reduced oxidative stress level, significantly promoted ischemic limb damaged muscle regeneration and motor function recovery, then, aberrant expression of miRNAs in ischemic skeletal muscles were determined by microarray analysis, combine with the results of the RT-qPCR, the miR-133b-3p was proved to be the specific miRNA. In vitro, our results revealed that PC induced the overexpression of miR-133b to activate the p38-MAPK signal pathway and increased the myogenic differentiation-related molecules expression, which eventually promoted myotubes formation. Furthermore, MKP1 was confirmed a direct target gene of miR-133b.

Conclusion: Our results suggest that PC display skeletal muscle protective properties that are mediated by miR-133b /MKP1/ p38-MAPK signal axis, offering a novel therapeutic opportunity for limb ischemic injury.

\section{Background}

Peripheral arterial disease (PAD) is a vascular disease that derives and develops from atherosclerosis (1), it is often accompanied by diabetes and coronary artery (2) disease .Critical limb ischemia (CLI) is the most widespread and severe clinical disorder of PAD, which cause progressive complications, such as intermittent claudication, gangrene and foot ulceration, eventually leading to morbidity and mortality (3). Reduced blood supply inevitably leads to skeletal muscle damage. Then, even if the blood supply of the limb can be recovered by standard surgical treatment effectively (4), tissue damage will still be exacerbated by ischemia-reperfusion and ischemic necrosis reoccurrence (5). Oxidative stress is one of crucial determinants contributes to limb ischemia, in addition, ischemic injury of the limb lead to reactive oxygen species (ROS) and inflammation increased, aggravate tissue damage $(5,6)$ and hinder the muscle repair and regeneration (7). 
In response to these damage, skeletal muscle satellite cells (SKMSCs), a population of stem cells, are activated and recruited to participate in muscle repair and regeneration (8-11). During this process, quiescent satellite cells are activated and differentiated into skeletal muscle cells (12) accompanied with muscle regulatory factors (MRF) expression, including myogenic differentiation antigen $D$ (MyoD), myogenic factor 5 (Myf5), myogenin and MRF4 (13-15). Accumulating evidence affirmed that the interventions which reduce oxidative stress are beneficial for muscle regeneration when muscles suffer from ischemic damage $(7,16,17)$. Proanthocyanidins $(P C)$, a bioflavonoid widely distributed in plants, which are extracted from polyphenol $(18,19)$, polyphenol has been proved to play strong antioxidant and scavenge oxygen fee radical effect $(20,21)$ to protect various organs in ischemia or ischemia-reperfusion injury $(22,23)$. Recent research has shown that PC therapy in diabetic mice can effectively reduce the oxidative stress of skeletal muscle and alleviate the severe endoplasmic reticulum stress under high glucose condition (24). Other studies also have shown that polyphenol extracts played an important role to protect ischemic limb $(13,25)$. Although the beneficial effects of polyphenol in critical limb ischemia are promising, the role and related molecular mechanism of PC are still unclear.

MicroRNAs (miRNAs) are endogenous short non-coding RNAs that fulfill post-transcriptional regulation cellular functions generally by interaction with the target genes (26), which have been implicated in many pathophysiological processes of PAD (27). Our previous series of studies have been screened and verified 24 aberrantly expressed miRNAs in the plasma and tissues of arteriosclerosis obliterans (ASO) patients (28). Among them, the function of miR-4463 in human umbilical vein endothelial cells was investigated in depth, and we demonstrated that it involved in limb ischemic regulation by inducing oxidative stress (29) and promote cell apoptosis (30). Recent studies have also confirmed the key role of miRNAs in regulating myogenic differentiation (31-33), which may also be achieved by directly or indirectly regulating genes related to oxidative stress (34), such as myomiRs miR-1/206 and the miR-133a/b. As mentioned above, Kozakowska et al (35). confirmed that HMOX1 downregulated miR-1/206 and miR-133a/b to inhibit the myogenic differentiation. It seems that finding potential inhibitors and in-depth exploration of its molecular mechanism may be helpful to provide new therapeutic strategies for protecting damaged muscle. In summary, we speculated that PC is just such an antioxidant, which exerts an important protective role in critical limb injury by regulating specific miRNA to promote SKMSCs differentiation and damaged muscle regeneration.

In this study, after inducing muscle ischemia models in vitro and in vivo, the effects of PC on ischemia injury muscle regeneration and SKMSCs differentiation were investigated. Then, muscle tissue treated with PC in hind limb ischemic mice was obtained, miRNAs profile of which was determined to screen altered miRNAs, combined with the results of RT-qPCR, the miR-133b was proved to be the specific miRNA which most obvious changed. The relationships between the signal pathways mediated by miR-133b with myogenic differentiation associated molecules and the underlying mechanisms were further explored.

\section{Methods}




\section{Animal experiment and limb ischemia model}

Thirty-two C57BL/6 mice (male; 22-25g,10-12weeks) were divided into four groups randomly. Mice were anesthetized by intra-peritoneal administration of $1 \%$ pentobarbital sodium $(10 \mathrm{ml} / \mathrm{kg})$. As showed in Supplementary Fig. 1A, unilateral hind limb ischemia was induced by 4 different surgical approaches as follows. Model1: Double ligation of the proximal and distal end of femoral artery (36), Model2: single ligation of the distal end of femoral artery (37), Model3: single ligation of the femoral artery between the superficial circumflex iliac artery and profunda femoral artery, Model4: combined the ligation sites of model 2 and model3. The latter two models are new approaches. Four groups mice were observed from days 0 to 21. To investigate the effect of PC on limb ischemia mice, thirty-six mice, specification as mentioned above, were selected and divided into three groups randomly after limb ischemia by model1, they were treated via intraperitoneal injection daily from days 0 to 21 with $\mathrm{H}_{2} \mathrm{O}$ or PC $(1 \mathrm{mg} / \mathrm{kg}$ or 20 $\mathrm{mg} / \mathrm{kg}$ ) (Sigma-aldrich, St. Louis, MO, USA). Postcava plasma and gastrocnemius were collected at days 7 and 21. Mice shown in this paper were purchased from Tengxin Biotechnology Research Laboratory (Chongqing, China). Animal experiment approved by the Laboratory Animal Welfare and Animal Ethics Committee of Southwest Medical University. The study conforms to the Guide for the Care and Use of Laboratory Animals published by the Sichuan Institutes of Health and was performed after institutional approval. Surgical approaches, detection and specimen collection standards were conducted according to the method reported in the classic literature (37).

\section{Laser doppler perfusion imaging}

Blood perfusion were scanned by the laser Doppler (Moor Instrumets, UK) at preoperative, postoperative 30 min, days 7, 14 and 21. The paws are taken as the regions of interest (ROI) to assessed for quantification of perfusion (Perfusion ratio $=$ ischemic/ non-ischemic paw $\times 100 \%)(37)$.

\section{Limb motor function assessment}

The foot movement of mice were investigated by score system as follows $(16,38): 4$, unrestricted movement; 3 , use of complete foot but toe movement restricted; 2 , use of the sole but no toes flexion (toe damage); 1 , use of the leg (food damage); 0 , drag foot limping (foot necrosis).

\section{Histological and immunofluorescence analysis}

Gastrocnemius was fixed with $4 \%$ paraformaldehyde. Tissues were embedded in paraffin and stained with hematoxylin and eosin (HE) for observation by microscope (Olympus, Japan). The central nuclei fibers (regenerating fibers) was counted in total muscle fibers of cross-sectional areas (4 samples/group) under microscope (16). Tissues immunofluorescent staining was performed as described previously (39). Quantification the number of myogenin ${ }^{+}$cells per field in 5 random areas of different samples of each group were counted (40). The primary antibody: anti- myogenin (Santa Cruz, USA). Images were obtained using laser scanning confocal microscope (Leica, Wetzlar, Germany). Images analyses and quantifications were performed using ImageJ software (Version 3.2). 


\section{Oxidative stress measurement}

Oxidative stress levels in postcava plasma and ischemia gastrocnemius were evaluated through Malondialdehyde (MDA) level by thiobarbituric acid reactive substances (TBARS) kit (ENZO, Farmingdale, NY, USA). According to the manufacturer's instructions, the absorbance of TBARS were measured at 532 nm using microplate reader (Thermo Fisher, Waltham, MA, USA). ROS production in cells were evaluated through Reactive Oxygen Species Assay Kit (Beyotime, China). Briefly, 2,7-dichlorofluorescein diacetate (DCFH-DA) was added to the cells and incubated at $37^{\circ} \mathrm{C}$ for $20 \mathrm{~min}, \mathrm{DCFH}-\mathrm{DA}$ fluorescence was analyzed by flow cytometer (BD FACSVerse, BD Biosciences Pharmingen) and detected by laser scanning confocal microscope (Leica, Wetzlar, Germany).

\section{Microarray analysis}

The RNA from mice ischemia gastrocnemius samples were labeled by miRCURY ${ }^{T M} \mathrm{Hy} 3^{T M} / \mathrm{Hy} 5^{\text {TM }}$ Power labeling kit (Exiqon, Vedbaek, Denmark). After stopping the labeling procedure, according to array instruction, the miRCURYTM LNA Array (v.19.0) (Exiqon) was used to hybridize the labeled samples. Then the Axon GenePix 4000B microarray scanner (Axon Instruments, CA) were used to scan the slides. GenePix pro V7.0 software (Axon) was used to read the raw intensity of the image. MiRNA data were obtained by Median Normalization Method.

\section{Cell culture and vitro ischemia}

Primary human skeletal muscle satellite cells (HSKMSCs) were purchased from ScienCell Research Laboratories (Carlsbad, CA, USA). The complete medium (ScienCell) contain $5 \%$ fetal bovine serum (FBS), $1 \%$ HSKMSC growth factor, $1 \%$ penicillin and streptomycin. Logarithmic second to fourth generation cells were used in this study. Hypoxic-ischemic condition ( $1 \% \mathrm{FBS}, 1 \% \mathrm{O}_{2}$ ) were used to construct cell models cells. Cells were first incubated in normal condition ( $\left.5 \% \mathrm{FBS}, 21 \% \mathrm{O}_{2}\right)$, when the adherent cell density was $70 \%$, cells were treated with different concentrations of PC or saline for 3 or 5 days under hypoxicischemic condition to analysis. The medium was refreshed every 2 days.

\section{Transfection}

miR-133b mimic (50 nmol/L) (sequence: UUUGGUCCCCUUCAACCAGCUA) and negative control miR-133b mimic NC (50 nmol/L) (sequence: UUUGUACUACACAAAAGUACUG), miR-133b inhibitor (100 nmol/L) (sequence: UAGCUGGUUGAAGGGGACCAAA) and miR-133b inhibitor NC (100 nmol/L) (sequence: CAGUACUUUUGUGUAGUACAA), si-MKP1 (si-h-DUSP1_103) (sequence: GGACTAATCGAGTCAAGCT) were all purchased from RiboBio Co., Ltd. (Guangzhou, China). After transfection for $12 \mathrm{~h}$, the medium was refreshed and HSKMSCs were incubated under hypoxic-ischemic condition for 3 days to analysis.

\section{RNA extraction and real-time qPCR}

Total RNA was extracted by Trizol (ABI, USA). According to the miScript II RT Kit (QIAGEN, Duesseldorf, Germany) technical instruction, 500 ng RNA was reverse transcribed to cDNA. To quantitative analysis of 
RNA expression levels. CDNA, used as a template, complexed with primers (QIAGEN) for RT-qPCR by miScript SYBR Green PCR Kit (QIAGEN), then performed using ABI StepOne Plus PCR system (ABI, USA). SnRU6 (U6) was used as reference genes, and data analysis were conducted using the $2^{-\triangle \triangle C t}$ method.

\section{Western blot}

Total protein from gastrocnemius and HSKMSCs were extracted by lysing with RIPA buffer, protein was separated on SDS-PAGE gels and transferred (Bio-Rad, USA) on polyvinylidene difluoride membranes (Millipore, Billerica, USA). Membranes were blocked with nonfat milk and subsequently incubated with primary antibody at $4^{\circ} \mathrm{C}$ overnight, then membranes were incubated with second antibody for $1 \mathrm{~h}$ at $37^{\circ} \mathrm{C}$. Tubulin was used as loading control. The primary antibodies: anti-MKP1(, Abcam, UK), anti-MyoD (Santa Cruz, USA), anti-myogenin (Santa Cruz, USA), anti-MHC (Abcam, UK), anti-p38-MAPK囚Cell Signaling Technology, USA), anti-p-p38-MAPK囚Cell Signaling Technology, USA), anti-Pax7 (Affinity, USA). Second antibody: horseradish peroxidase-conjugated anti-mouse lgG or anti-rabbit lgG (Beyotime, China). Images were acquired by Fusion solo 4 (Vilber Lourmat Sté, Paris, France) and quantitative analysis was performed using FusionCapt Advance Solo 4 software.

\section{Immunofluorescence staining}

HSKMSCs were fixed with $4 \%$ paraformaldehyde for $15 \mathrm{~min}$, then treated with $0.2 \%$ Triton X-100 for 10 min. Cells were blocked with $10 \%$ goat serum subsequently incubated with primary antibody at $4^{\circ} \mathrm{C}$ overnight. Then, cells were incubated with secondary antibody at $37^{\circ} \mathrm{C}$ for $1 \mathrm{~h}$. The nuclei were stained using DAPI at $37^{\circ} \mathrm{C}$ for $10 \mathrm{~min}$. Images were obtained using laser scanning confocal microscope (Leica, Wetzlar, Germany). Quantification the number of myogenin ${ }^{+}$cells per field in 5 random areas of different samples of each group were counted (40). Fusion indices were calculated based on $\mathrm{MHC}^{+}$cells presented in panel. Fusion index was counted as the percentage of total nuclei present in multinucleated myotubes. The primary antibodies: anti-myogenin (Santa Cruz, USA), anti-MHC (Abcam, UK). Images analyses and quantifications were performed using ImageJ software (Version 3.2).

\section{Bioinformatic analyses}

As showed in Supplementary Fig 2, the miRNA target genes were predicted by finding the common intersection between Target Scan and miRanda. Then, functional classification of the target genes was performed using gene Ontology (GO) analysis and signal pathways were analyzed using KEGG pathway. Finally, predicting the target protein-protein interactions encoded by the target genes and excluding unrelated proteins were carried out by the STRING database.

\section{Luciferase reporter assay}

Human wild type MKP1 3 '- UTR and mutant MKP1 3 '- UTR were subcloned into psiCHECK 2 vector to acquire the recombinant plasmid. Her 293T cells were cultured in a 96-well plate until density reached 50$70 \%$. Cells were co-transfected with wild-type MKP1 3 '-UTR plasmids or mutant MKP1 3 '-UTR plasmids 
and miR-133b mimic or miR-133b mimic NC. The medium was refreshed after $6 \mathrm{~h}$. Cells were collected after 48 hours, according to manufacturer' instruction, Promega Dual-Luciferase system were used to record the Firefly luciferase value and Renilla luciferase value.

\section{Statistical analysis}

Experiments were conducted at least in triplicate. Data were analysed using SPSS version 23.0 software and GraphPad Prism version 7.0. Comparison between two groups were analyzed by Independent sample t-test. Multiple comparisons were analyzed by One-way ANOVA. Pairwise comparison was analyzed by LSD test. Data are expressed as the mean \pm SEM, $P<0.05$ was considered to statistically significant difference.

\section{Results}

\section{model 1 was the longest ischemia duration and simplest operation among the fourmodels}

The mice unilateral limb ischemia model, which mimics critical limb ischemia in humans, was induced in mice and treated with four different surgical methods (Supplementary Fig 1a). After limb ischemia surgery, four groups mice were observed from days 0 to 21 .

Limb ischemia inevitably affects motor function, as shown in Supplementary Fig $1 \mathrm{~b}$, we found that the motor function recovery of model 2 and model 3 were significantly faster than model 1 and model 4 at day 14 and basically returned to normal.

To investigate the recovery of blood perfusion, the blood perfusion was measured by Laser Doppler perfusion imaging (Supplementary Fig 1c). The result showed the blood perfusion percentage of model1 was significantly lower than model 2 and model 3 at the days 0,14 and 21 , but there was no significant difference between model 1 and model 4 , the result indicated that the recovery of blood perfusion of model 1 and model 4 were slower than model 2 and model3.

The satellite cells are activated to differentiate and fuse into myotube to promote skeletal muscle regeneration when suffered from ischemic damage. Regenerated skeletal muscle presents as central nuclear fibers, while mature skeletal muscle presents as eccentric nuclear fibers. The result showed the regenerated muscle fibers ratio of model 1 was significantly higher than model 2 and model 3 at days 7 and 21. No significantly difference was found between model1 and model4 (Supplementary Fig 1d).

Our result indicated that model 1 and model 4 had were longest ischemia duration. Compared with model4, model 1 may be a better choice due to its simple operation. Taken together, model 1 was used in subsequent experimental studies.

PC protect ischemic damaged skeletal muscle by reducing the oxidative stress and promoting regeneration 
As shown in Fig. 1a, the unilateral limb ischemia mice were performed by model 1 method. After surgery, mice were treated with $\mathrm{H}_{2} \mathrm{O}, 20 \mathrm{mg} / \mathrm{kg}$ PC or $1 \mathrm{mg} / \mathrm{kg} \mathrm{PC}$, respectively. The results showed that the recovery of limb motor function in each group was time-dependent, and returned to normal at day 21 . And $20 \mathrm{mg} / \mathrm{kg}$ PC were significantly faster than that in $\mathrm{H}_{2} \mathrm{O}$ and $1 \mathrm{mg} / \mathrm{kg} \mathrm{PC} \mathrm{(Fig.} \mathrm{1b).} \mathrm{Analysis} \mathrm{of} \mathrm{tissue}$ regeneration in ischemic gastrocnemius at days 7 and 21 revealed that $20 \mathrm{mg} / \mathrm{kg} P C$ treated mice contained a higher number of regenerating myofibers than that in $\mathrm{H}_{2} \mathrm{O}$ and $1 \mathrm{mg} / \mathrm{kg} \mathrm{PC} \mathrm{(Fig.} \mathrm{1c).}$ However, there were no evidently difference between $\mathrm{H}_{2} \mathrm{O}$ group and $1 \mathrm{mg} / \mathrm{kg} \mathrm{PC}$ group neither in motor function recovery nor in muscle regeneration. In order to further evaluate the muscle regeneration, the expression of myogenin was been detected by immunofluorescence analysis. Compared with saline, the number of myogenin positive cells in $20 \mathrm{mg} / \mathrm{kg}$ PC group were significantly increased at day 7 (Fig. 1d). To investigate whether these changes were due to differences in oxidative stress, the MDA levels were further detected both in plasma and in ischemia muscles at days 7 and 21 (Fig. 1e). Compared with $\mathrm{H}_{2} \mathrm{O}$, $20 \mathrm{mg} / \mathrm{kg}$ PC induction resulted in significantly lower MDA levels both in plasma and ischemic muscle at day 7. Compared with $1 \mathrm{mg} / \mathrm{kg}$ PC, $20 \mathrm{mg} / \mathrm{kg}$ PC induction resulted in significantly lower MDA plasma levels at day 7. Meanwhile, no significantly difference was found among three groups at day 21.

These results suggested that different concentrations of PC cause different effects on ischemic muscle, that is, $20 \mathrm{mg} / \mathrm{kg}$ PC can protect ischemia-induced muscle damage, which may be achieved by resisting oxidative stress and promoting ischemic muscle regeneration, $\mathrm{H}_{2} \mathrm{O}$ and $1 \mathrm{mg} / \mathrm{kg} P C$ have no such effect. Considering the regeneration of ischemic muscle was most obvious at day 7 , so unilateral limb ischemia mice treated with $20 \mathrm{mg} / \mathrm{kg} \mathrm{PC}$ for 7 days were chosen in the following study.

\section{PC promote HSKMSCs myogenic differentiation in vitro under hypoxic-ischemic condition}

To investigate the functional role of PC in HSKMSCs myogenic differentiation under hypoxic-ischemic condition, we first incubated HSKMSCs in media with saline or different concentrations of $P C(5,10,15$, $20 \mathrm{ug} / \mathrm{ml}$ ) for $24 \mathrm{~h}$. As shown in Fig. 2a, with PC concentration increased above $5 \mathrm{ug} / \mathrm{ml}$, cell status of HSKMSCs got poor, which suggested that PC concentration no more than $5 \mathrm{ug} / \mathrm{ml}$ may be suitable induction concentration.

Quiescent satellite cells express the transcription factor Pax7, to evaluate the effect PC on satellite cell at baseline, we treated the cells with saline, $2.5 \mathrm{ug} / \mathrm{ml} \mathrm{PC}$ or $5 \mathrm{ug} / \mathrm{ml} \mathrm{PC}$ for 3 and 5 days in the normal condition, and then detected the expression of Pax7 by western blot (Fig. 2b) and immunofluorescence (Fig. 2c). The results showed that there was no significant difference in the expression of Pax7 among three groups.

When SKMSCs were subjected to hypoxic-ischemic condition, cells are activated to induced cell fusion and multinucleated myotubes formation. Cells were treated with saline, $2.5 \mathrm{ug} / \mathrm{ml} \mathrm{PC} \mathrm{or} 5 \mathrm{ug} / \mathrm{ml} \mathrm{PC} \mathrm{for} 3$ and 5 days. The results showed that in the normal condition, there were none myotubes been investigated. While in hypoxic-ischemic condition, myotubes were presented in three groups, but the degree of differentiation was inconsistent: when the differentiated cells been investigated using 
microscope (Fig. 2d), compared with the saline group, the PC group induced more myotubes, whether the concentration of $\mathrm{PC}$ is $2.5 \mathrm{ug} / \mathrm{ml}$ or $5 \mathrm{ug} / \mathrm{ml}$. Then, we analyzed the myotubes formation by immunofluorescence analysis (Fig. 2e). Compared with saline, the number of multinucleated myotubes in PC group were significantly increased. Meanwhile, no significantly difference was found between 2.5 $\mathrm{ug} / \mathrm{ml} \mathrm{PC}$ and $5 \mathrm{ug} / \mathrm{ml} \mathrm{PC}$. And the number of myotubes at day 5 was more than that at day 3 . Moreover, myogenin, a marker indicative myogenic differentiation, was found mainly located in the nucleus, while MHC was mainly located in the cytoplasm (Fig. 2e).

Taken together, these data suggest that PC promote myogenic differentiation of HSKMSCs under hypoxic-ischemic condition.

\section{PC induce the expression of myogenic marker genes both in vivo and in vitro}

After being induced by PC in vivo and in vitro, some myogenic differentiation marker proteins are examined. At same time, studies have showed that p38-MAPK signaling pathway may involve in myogenic differentiation (41), so the expression of p38-MAPK and p-p38-MAPK was been investigated. In the ischemia gastrocnemius of mice, Western blot results showed that the protein level of MyoD and pp38-MAPK in PC-treated were remarkably increased compared to that in $\mathrm{H}_{2} \mathrm{O}$-treated, but without an effect on p38-MAPK. (Fig. 3a).

Consistent with the result in vivo, we also got similar results in vitro, two dosage of $\mathrm{PC}$ all improved the expression of myogenic related protein, such as MyoD, myogenin and MHC (Fig. 3b). Moreover, the protein expression in $2.5 \mathrm{ug} / \mathrm{ml} \mathrm{PC}$ was more obvious than that in $5 \mathrm{ug} / \mathrm{ml}$ and increased over time. Taken together, we choose $2.5 \mathrm{ug} / \mathrm{ml} \mathrm{PC}$ treatment in the following study.

To further investigate whether PC also involves oxidative stress in addition to affecting myogenic differentiation, the ROS levels were further detected in HSKMSCs under hypoxic-ischemic condition at days 1,3 and 5 (Fig. 3c, 3d). The results showed that elevated ROS level was induced by hypoxicischemic condition. Compared with saline, two dosage of PC induction all resulted in significantly lower ROS levels. Compared with $2.5 \mathrm{ug} / \mathrm{ml} \mathrm{PC,} 5 \mathrm{ug} / \mathrm{ml} \mathrm{PC}$ induction resulted in lower ROS levels relatively (Fig. 3c, d).

\section{PC induced the expression of miR-133b to promote myogenic differentiation through p38-MAPK pathway under hypoxic-ischemic condition}

To investigate whether miRNAs are involved in PC mediated myogenic differentiation when limbs suffer from ischemic injury. Unilateral limb ischemia mice were treated with $20 \mathrm{mg} / \mathrm{kg} \mathrm{PC}$ and $\mathrm{H}_{2} \mathrm{O}$ for 7 days, ischemic gastrocnemius was collected to detect the significant differentially expressed miRNAs using microarray analysis, eight significant differentially expressed genes were analyzed by clustering analysis (Fig. 4a). Combine with the results of the RT-qPCR, the miR-133b-3p of mice was significant elevated and its gene sequence was consistent with the miR-133b of human. And they sharply increased both in vivo and vitro with PC treatment (Fig. 4b). 
We further transfected HSKMSCs with miR-133b mimic, inhibitor or negative control, then followed by hypoxic-ischemic treatment for 3 days to determine the protein expression. The results showed that upregulation of miR-133b remarkably improved the expression of MHC, MyoD, myogenin and p-p38 MAPK compared to miR-133b mimic NC. Correspondingly, downregulated miR-133b inhibited the expression of these proteins and partially reversed the effect of PC on these proteins (Fig. 4c, 4d).

We further analyzed the myogenic differentiation in HSKMSCs by immunofluorescence analysis. As shown in Fig. 4e, after transfection with miR-133b mimic, the number of multinucleated myotubes was significantly increased compared with transfection with miR-133b mimic NC. On the contrary, after downregulated miR-133b, the number of multinucleated myotubes was remarkably inhibited.

These results suggested that miR-133b induced by PC, was involved in myogenic differentiation by regulating myogenic associated gene through p38-MAPK pathway.

\section{MiR-133b directly targets MKP1 in HSKMSCs}

miRNAs posttranscriptionally inhibit the translation of target genes, to investigate which target genes are involved in miRNAs mediated myogenic differentiation when ischemic limbs treated with PC.

Bioinformatic analyses were used to predict miRNA target (Supplementary Fig 2). The result shown that MKP1 may be a candidate target gene for miR-133b, the next experiment was to confirm it. Firstly, the expression of MKP1 were obviously attenuated in vivo and in vitro with PC treatment (Fig. 5a). Then, upregulated miR-133b obviously inhibited the MKP1, as expected, inhibition of MKP1 was indeed reversed by downregulated miR-133b (Fig. 5b). These data suggest that regulation of miR-133b altered MKP1 protein expression in HSKMSCs.

Secondly, As shown in Fig. 5c, silencing of MKP1 facilitated the p-p38-MAPK and promoted the expression of MHC, MyoD, myogenin. We further both silencing of MKP1 and inhibit miR-133b in HSKMSCs, the results showed that silencing of MKP1 had the ability to block the miR-133b inhibitor mediated inactivated myogenic related genes.

To analyzed whether miR-133b directly targets MKP1, As shown in Fig. $5 \mathrm{~d}$, the predicted interactions between miR-133b and its target sites in the MKP1 3'-UTR showed that good base pairing with the seed region. We next used Luciferase reporter assay to investigated whether miR-133b directly bind to the $3^{\prime}-$ UTR seed sequence of MKP1 mRNA. Compared to NC, the results showed that upregulation of miR-133b remarkably inhibited the luciferase reporter activity. In addition, upregulation of miR-133b suppressed the reporter activity were reversed by the mutations, which eliminated the predicted binding site with MKP1 in the MKP1 3'-UTR.

Briefly, the results suggested that miR-133b negatively regulate MKP1 expression by directly target it.

\section{Discussion}


With the increasing population and proportion of PAD patients, limb ischemic injury has become one of the main factors causing limb disability (42). The standard therapies, such as traditional surgery or endovascular intervention, are not particularly effective or appropriate (43), new therapeutic options need to be continuously explored. Regenerative medicine and in particular skeletal muscle satellite cell-based therapy (44), has shown some early promise. Our study revealed that PC reduced the oxidative stress level, promoted myogenic differentiation of HSKMSCs and renovated the damaged muscle fibers, thereby promoting the motor function recovery. Then, the microarray analysis identified altered miR-133b expression in ischemic muscle treated with PC. And verified that by up-regulating miR-133b, PC activates the p38-MAPK signal and myogenic differentiation-related molecules, which eventually promote HSKMSCs differentiation and myotubes formation, thereby exerting an important protective effect. Research on the mechanism further confirmed that MKP1 is a direct target gene of miR-133b. To our knowledge, this is the first report that PC induce the SKMSCs myogenic differentiation by regulating miR133b/MKP1/p38-MAPK signal axis, to promote ischemic damaged skeletal muscle regeneration.

Animal models are useful for both studying the pathology of limb ischemia injury and testing therapeutic strategies in vivo, several animal models of unilateral hindlimb ischemia have been used to simulate clinical PAD $(45,46)$. Although most of the models are generally induced by blocking the blood supply to the hind limbs, the specific method is still slightly different. A relatively common model is to double ligation of the proximal and distal end of rodent femoral artery, whereas Limbourg (37) established another hind limb ischemia model by ligating the distal end of mice femoral artery separately. As for these PAD models, the degree of limb ischemia, the time to blood flow recovery, and the effect on muscle cell regeneration may be different, but there are few related compare studies in the literatures. To identify a relatively suitable and stable animal model of critical limb injury, we compared four different mouse limb ischemia models, the model 1 method followed by Couffinhal (36) and model 2 method followed by Limbourg (37), methods of model 3 and model 4 were new approaches. The results showed after the operation, both blood flow and motor function in the four models gradually recovered in a time-dependent manner. Among them, model 1 and model 4 recovered more slowly than model 2 and model 3 in the designated time, no significant differences were found between model 1 and model4. The regenerated muscle fibers ratio of model 1 and model 4 were obviously higher than model 2 and model 3 , which suggested that model 1 and model 4 induce more muscle cell regeneration. It appears that the above four models may induce different degrees of limb ischemia in mice, the pathophysiological conditions induced by model 1 and model 4 were more suitable for the current experimental conditions because of longer lasting ischemic time and longer treatment time window. Compared with model4, Model1 may be a better choice due to its ease to operation.

Proanthocyanidins (PC), a bioflavonoid widely distributed in plants, is widely derived from polyphenol extracts of grape seeds, tea leaves, propolis. polyphenol extracts have been proved that play strong antioxidant stress (47), cardiovascular protection (22), metabolic regulation (48), anticancer (49) and other effects. Polyphenol extracts, have attracted increasing attention for their protective role in lower limb ischemia. Its function is mainly obtained by effectively promoting the activation of SKMSCs and regeneration of ischemic skeletal muscle (50). Recent studies confirmed that PC protected various organs 
from ischemia or ischemia-reperfusion injury by improving the energy metabolism and reducing oxidative stress injury, thereby reducing the cell apoptosis (5). Nevertheless, the benefits of PC in critical limb ischemia, especially its specific molecular mechanism, needs further exploration.

After PC treated the mice model subjected to unilateral limb ischemia, it resulted in faster recovery of motor function, decreased MDA level of plasma and gastrocnemius, and also inhibited the level of ROS in HSKMSCs. Through direct or indirect methods in vitro and in vivo, the results proved that PC reduced ROS level under hypoxic-ischemic condition. Some studies showed that oxygen free radicals generated after muscle injury, which will lead to tissue necrosis and cell apoptosis, thus hindering the repair of injury muscle $(7,16)$. It seems that preventing excessive oxidative stress is beneficial for muscle regeneration. Kozakowska et al. (35) found that HMOX1 (an antioxidant defense enzyme) can reduce the production of MyoD by downregulating the expression of mir-1/206 and mir-133a/b, thus inhibiting the differentiation of myoblast cells. we speculated that PC promotes ischemic limb function recovery at least in part associated with reducing oxidative stress. In addition to this, our study also confirmed that PC increases the number of central nuclei myofibers, indicating that PC may promote muscle regeneration, in order to further explore it in vitro, we investigated the functional role of PC in HSKMSCs myogenic differentiation under hypoxic-ischemic condition, and found PC obviously increased the number of multinucleated myotubes. After limb ischemia, skeletal muscle satellite cells are activated, some cells proliferate massively through symmetric division, thus entering the process of cell differentiation, while, others are added to the satellite cell pool in a resting state through asymmetric division $(41,51)$. Activated skeletal muscle satellite cells proliferate and differentiate into muscle cells to promote muscle regeneration accompanied with a series of proteins being activated. MRFs family are regarded as markers of myogenic differentiation, composed of four muscle-specific transcription factors: MyoD, Myf5, myogenin and MRF4 (52). Myf5 and MyoD have similar functions, which can regulate early myogenic differentiation and determine the formation of muscle (14). MyoD is a key myogenic transcription factor in muscle regeneration $(53,54)$, mainly regulates some muscle specific genes, such as myosin heavy chain (MHC) and myogenin. Myogenin and MRF4 play a decisive role in the formation of multinucleated cells and myotube. The expression of MHC gene marks the final stage of myogenic differentiation. Based on this, we tested whether PC affects the expression of these muscle differentiation-related proteins both in ischemic muscle tissue and in hypoxic-ischemic HSKMSCs. The results verified PC evidently promoted the upregulated expression of MyoD, myogenin as well as MHC. The above data clearly confirm that PC exerts an important protective role in ischemic damaged muscle. By inhibiting oxidative stress, it promotes muscle satellite cell differentiation and myotube formation, and ultimately promotes muscle regeneration and injury repair. However, in this process, the molecular mechanism of skeletal muscle cell regeneration mediated by $\mathrm{PC}$ is unclear.

MiRNAs are involved in post-transcriptional regulation of gene expression and have been implicated in PAD $(28,55)$ and critical limb injury, which have been confirmed by our pool term and others studies. Therefore, we hypothesized that specific miRNAs are also involved in the molecular mechanism of PC protecting hind limb ischemia injury. In order to validate it, we screened the aberrantly expressed miRNAs 
in ischemic muscle tissue treated with $\mathrm{PC}$ or $\mathrm{H}_{2} \mathrm{O}$ using microarray and ascertained miR-133b is involved in this pathophysiologic process of CLI in vivo. The miR-133a /b family belong to myogenic miRNAs (33), which have been described closely related to myogenic differentiation. In $\mathrm{C} 2 \mathrm{C} 12$ cells, miR-133 promoted the expression of serum response factor (SRF) to participate in the repair of injury skeletal muscle (56, 57). Similarly, our study revealed that PC upregulated the expression of miR-133b to promote skeletal muscle repair and cell regeneration. Next, we explored the effects of regulating miR-133b on myogenic differentiation-related molecules. The result showed that up-regulating miR-133b activates these proteins, and inhibiting miR-133b has the opposite effect and can also diminished the effect of PC on HSKMSCs. Some studies have shown that p38-MAPK signaling pathway involved in the proliferation and differentiation of skeletal satellite cells $(41,58,59)$. The inhibition of p38-MAPK suppresses the myogenic differentiation in satellite cells $(41,58)$. We also detected the increased expression of p38-MAPK whether in ischemic limb tissue or in hypoxic-ischemic SKMSCs treated with PC, and up-regulated miR-133b obviously activated p38-MAPK signal, vice versa. Together, after muscle ischemic injury, PC induced miR$133 \mathrm{~b}$ expression and activated downstream p38-MAPK signal to promote muscle regeneration.

The miRNAs may guide ribosome binding to the 3'-UTR of the target genes and posttranscriptionally suppress the translation of the target genes. Here we confirmed that sphatmitogen-activated protein kinase phoase 1 (MKP1) was directly regulated by miR-133b and it was a direct target gene. It was reported that atherosclerosis could be decreased due to chronic deficiency of MKP1, via mechanisms including macrophage migration impaired and extracellular signal-regulated kinase signaling defective (60). Recent study revealed that inhibit MKP1 can promote the expression of Mef2c to activate Notch signaling pathway, thus protecting the injury skeletal muscle (61). In this study, we confirmed PC reduced the expression of MKP1 in vivo and vitro, then miR-133b directly targeted $M K P 1$ and negatively regulated its expression. To further elaborate on the mechanism of miR-133b targeted MKP1 to promote cell differentiation, we inhibited MKP1 and found it not only promoted myogenic differentiation but also activated p38-MAPK signal on HSKMSCs. Taken together, these data suggested that after limb ischemic injury, PC activated miR-133b to promote the myogenic differentiation of HSKMSCs by directly targeting and regulating MKP1 and its downstream p38-MAPK signaling pathway.

In summary, our data partly account for the potential molecular mechanism of PC therapy in PAD associated critical limb injury, which gives us a better understanding of the relationship between the regulated miR-133b expression and the myogenic differentiation of HSKMSCs under hypoxic-ischemic condition. Efforts should now be made to further investigate the therapeutic potential of $P C$ and/or premiR-133b for the treatment of PAD.

\section{Conclusion}

In conclusion, our data demonstrate that PC could reduce the oxidant stress and promote ischemic skeletal muscle regeneration, thereby promoting the motor function recovery. Mechanistically, PC activate HSKMSCs to promote the myogenic differentiation via miR-133b/MKP1/MAPK signal axis, thus promoting ischemic skeletal muscle regeneration and repairing the damaged skeletal muscles. 


\section{Abbreviations}

PAD: peripheral arterial disease; PC: Proanthocyanidins; miRNAs: MicroRNAs; HSKMSCs: human skeletal muscle satellite cells; CLI: critical limb ischemia; ROS: reactive oxygen species; SKMSCs: skeletal muscle satellite cells; MRF: muscle regulatory factors: MyoD: myogenic differentiation antigen D; Myf5: myogenic factor 5; MHC: myosin heavy chain; MDA: Malondialdehyde; TBARS: thiobarbituric acid reactive substances; DCFH-DA: DCFH-DA; FBS: fetal bovine serum; MKP1: mitogen-activated protein kinase phosphatase 1.

\section{Declarations}

\section{Acknowledgements}

Not applicable

\section{Authors' contributions}

X.Z.: conception and design, financial support, final approval of manuscript; S.C.: conception and design, performed research, cell experiments, data analysis and interpretation, manuscript writing; C.D.: conception and design, performed research, most of the animal experiment, data analysis and interpretation; C.Z.: manuscript editing and final approval of manuscript; L.P.: manuscript editing and final approval of manuscript. Q.Y.: data analysis and interpretation; F.W., Y.Z.: part of the animal experiment; P.Y., R.H.: collection and/or assembly of data.

Authors' information: Shi Chen and Chao Du are co-first author.

Funding: This work was supported by the Natural Science Foundation of Sichuan Province (No. 2018JY0408), the Joint Research project of Luzhou city and Southwest Medical University (No.2017LZXNYD-J18, 2019LZXNYDZ02), and Scientific Research Project of Sichuan Province Traditional Chinese Medicine Administration (2018JC040).

\section{Availability of data and materials}

The data that support the findings of this study are available from the corresponding author upon reasonable request.

\section{Ethics approval and consent to participate}

Animal experiment approved by the Laboratory Animal Welfare and Animal Ethics Committee of Southwest Medical University. The study conforms to the Guide for the Care and Use of Laboratory Animals published by the Sichuan Institutes of Health and was performed after institutional approval.

\section{Consent for publication}


Not applicable.

\section{Competing interests}

The authors declare no conflict of interest.

\section{Author details}

${ }^{1}$ Department of Thyroid and Vascular Surgery, the Affiliated Hospital of Southwest Medical University, Luzhou, China; ${ }^{2}$ Collaborative Innovation Center for Prevention and Treatment of Cardiovascular Disease of Sichuan Province, Southwest Medical University, Luzhou, China; ${ }^{3}$ Emergency Department, Zigong Fourth People's Hospital, Zigong, China; ${ }^{4}$ School of Medicine, Jiangnan University, Wuxi, China; ${ }^{5}$ School of Pharmacy, Chengdu Medical College, Chengdu, China; ${ }^{6}$ Department of Hepatobiliary Surgery, The Affiliated Hospital of Southwest Medical University, Luzhou, China; ${ }^{7}$ Key Laboratory of Medical Electrophysiology, Ministry of Education, Institute of Cardiovascular Research of Southwest Medical University, Luzhou, China; ${ }^{8}$ Department of Cardiology, the Affiliated Hospital of Southwest University, Luzhou,

China.

\section{References}

1. Weitz JI, Byrne J, Clagett GP, Farkouh ME, Porter JM, Sackett DL, et al. Diagnosis and treatment of chronic arterial insufficiency of the lower extremities: a critical review. Circulation. 1996;94(11):302649.

2. Fowkes FG, Rudan D, Rudan I, Aboyans V, Denenberg JO, McDermott MM, et al. Comparison of global estimates of prevalence and risk factors for peripheral artery disease in 2000 and 2010: a systematic review and analysis. Lancet (London, England). 2013;382(9901):1329-40.

3. Tendera M, Aboyans V, Bartelink ML, Baumgartner I, Clément D, Collet JP, et al. ESC Guidelines on the diagnosis and treatment of peripheral artery diseases: Document covering atherosclerotic disease of extracranial carotid and vertebral, mesenteric, renal, upper and lower extremity arteries: the Task Force on the Diagnosis and Treatment of Peripheral Artery Diseases of the European Society of Cardiology (ESC). European heart journal. 2011;32(22):2851-906.

4. Gray BH, Conte MS, Dake MD, Jaff MR, Kandarpa K, Ramee SR, et al. Atherosclerotic Peripheral Vascular Disease Symposium II: lower-extremity revascularization: state of the art. Circulation. 2008;118(25):2864-72.

5. Lejay A, Meyer A, Schlagowski Al, Charles AL, Singh F, Bouitbir J, et al. Mitochondria: mitochondrial participation in ischemia-reperfusion injury in skeletal muscle. The international journal of biochemistry \& cell biology. 2014;50:101-5. 
6. Sin TK, Pei XM, Teng BT, Tam EW, Yung BY, Siu PM. Oxidative stress and DNA damage signalling in skeletal muscle in pressure-induced deep tissue injury. Pflugers Archiv : European journal of physiology. 2013;465(2):295-317.

7. Zaccagnini G, Martelli F, Magenta A, Cencioni C, Fasanaro P, Nicoletti C, et al. p66(ShcA) and oxidative stress modulate myogenic differentiation and skeletal muscle regeneration after hind limb ischemia. The Journal of biological chemistry. 2007;282(43):31453-9.

8. Bischoff R, Heintz C. Enhancement of skeletal muscle regeneration. Developmental dynamics : an official publication of the American Association of Anatomists. 1994;201(1):41-54.

9. Chang NC, Rudnicki MA. Satellite cells: the architects of skeletal muscle. Current topics in developmental biology. 2014;107:161-81.

10. Wang YX, Rudnicki MA. Satellite cells, the engines of muscle repair. Nature reviews Molecular cell biology. 2011;13(2):127-33.

11. Kuang S, Gillespie MA, Rudnicki MA. Niche regulation of muscle satellite cell self-renewal and differentiation. Cell stem cell. 2008;2(1):22-31.

12. Kadi F, Charifi N, Denis C, Lexell J, Andersen JL, Schjerling P, et al. The behaviour of satellite cells in response to exercise: what have we learned from human studies? Pflugers Archiv : European journal of physiology. 2005;451(2):319-27.

13. Kim AR, Kim KM, Byun MR, Hwang JH, Park Jl, Oh HT, et al. Catechins activate muscle stem cells by Myf5 induction and stimulate muscle regeneration. Biochemical and biophysical research communications. 2017;489(2):142-8.

14. Rudnicki MA, Schnegelsberg PN, Stead RH, Braun T, Arnold HH, Jaenisch R. MyoD or Myf-5 is required for the formation of skeletal muscle. Cell. 1993;75(7):1351-9.

15. Cornelison DD, Wold BJ. Single-cell analysis of regulatory gene expression in quiescent and activated mouse skeletal muscle satellite cells. Developmental biology. 1997;191(2):270-83.

16. Togliatto G, Trombetta A, Dentelli P, Cotogni P, Rosso A, Tschöp MH, et al. Unacylated ghrelin promotes skeletal muscle regeneration following hindlimb ischemia via SOD-2-mediated miR221/222 expression. Journal of the American Heart Association. 2013;2(6):e000376.

17. Di Filippo ES, Mancinelli R, Marrone M, Doria C, Verratti V, Toniolo L, et al. Neuromuscular electrical stimulation improves skeletal muscle regeneration through satellite cell fusion with myofibers in healthy elderly subjects. Journal of applied physiology (Bethesda, Md : 1985). 2017;123(3):501-12.

18. Kumar R, Deep G, Wempe MF, Agarwal R, Agarwal C. Procyanidin B2 3,3"-di-O-gallate inhibits endothelial cells growth and motility by targeting VEGFR2 and integrin signaling pathways. Current cancer drug targets. 2015;15(1):14-26.

19. Lee TM, Charng MJ, Tseng CD, Lai LP. A Double-Blind, Randomized, Placebo-Controlled Study to Evaluate the Efficacy and Safety of STA-2 (Green Tea Polyphenols) in Patients with Chronic Stable Angina. Acta Cardiologica Sinica. 2016;32(4):439-49.

20. Daglia M. Polyphenols as antimicrobial agents. Current opinion in biotechnology. 2012;23(2):174-81. 
21. Nakayama T. Suppression of hydroperoxide-induced cytotoxicity by polyphenols. Cancer research. 1994;54(7 Suppl):1991s-3s.

22. Chang WT, Shao ZH, Yin JJ, Mehendale S, Wang CZ, Qin Y, et al. Comparative effects of flavonoids on oxidant scavenging and ischemia-reperfusion injury in cardiomyocytes. European journal of pharmacology. 2007;566(1-3):58-66.

23. Quintieri AM, Baldino N, Filice E, Seta L, Vitetti A, Tota B, et al. Malvidin, a red wine polyphenol, modulates mammalian myocardial and coronary performance and protects the heart against ischemia/reperfusion injury. The Journal of nutritional biochemistry. 2013;24(7):1221-31.

24. Ding Y, Dai X, Jiang Y, Zhang Z, Bao L, Li Y, et al. Grape seed proanthocyanidin extracts alleviate oxidative stress and ER stress in skeletal muscle of low-dose streptozotocin- and highcarbohydrate/high-fat diet-induced diabetic rats. Molecular nutrition \& food research. 2013;57(2):365-9.

25. Montesano A, Luzi L, Senesi P, Mazzocchi N, Terruzzi I. Resveratrol promotes myogenesis and hypertrophy in murine myoblasts. Journal of translational medicine. 2013;11:310.

26. Roberts TC. The microRNA Machinery. Advances in experimental medicine and biology. 2015;887:1530.

27. Stather PW, Sylvius N, Wild JB, Choke E, Sayers RD, Bown MJ. Differential microRNA expression profiles in peripheral arterial disease. Circulation Cardiovascular genetics. 2013;6(5):490-7.

28. He XM, Zheng YQ, Liu SZ, Liu Y, He YZ, Zhou XY. Altered Plasma MicroRNAs as Novel Biomarkers for Arteriosclerosis Obliterans. Journal of atherosclerosis and thrombosis. 2016;23(2):196-206.

29. Wang X, He X, Deng X, He Y, Zhou X. Roles of miR-4463 in H2O2-induced oxidative stress in human umbilical vein endothelial cells. Molecular medicine reports. 2017;16(3):3242-52.

30. He X, Du C, Zou Y, Long Y, Huang C, Chen F, et al. Downregulation of MicroRNA-4463 Attenuates HighGlucose- and Hypoxia-Induced Endothelial Cell Injury by Targeting PNUTS. Cellular physiology and biochemistry : international journal of experimental cellular physiology, biochemistry, and pharmacology. 2018;49(5):2073-87.

31. Sjögren RJ, Egan B, Katayama M, Zierath JR, Krook A. Temporal analysis of reciprocal miRNA-mRNA expression patterns predicts regulatory networks during differentiation in human skeletal muscle cells. Physiological genomics. 2015;47(3):45-57.

32. Horak M, Novak J, Bienertova-Vasku J. Muscle-specific microRNAs in skeletal muscle development. Developmental biology. 2016;410(1):1-13.

33. Mok GF, Lozano-Velasco E, Münsterberg A. microRNAs in skeletal muscle development. Seminars in cell \& developmental biology. 2017;72:67-76.

34. Mancinelli R, Di Filippo ES, Verratti V, Fulle S, Toniolo L, Reggiani C, et al. The Regenerative Potential of Female Skeletal Muscle upon Hypobaric Hypoxic Exposure. Frontiers in physiology. 2016;7:303.

35. Kozakowska M, Ciesla M, Stefanska A, Skrzypek K, Was H, Jazwa A, et al. Heme oxygenase-1 inhibits myoblast differentiation by targeting myomirs. Antioxidants \& redox signaling. 2012;16(2):113-27. 
36. Couffinhal T, Silver M, Zheng LP, Kearney M, Witzenbichler B, Isner JM. Mouse model of angiogenesis. The American journal of pathology. 1998;152(6):1667-79.

37. Limbourg A, Korff T, Napp LC, Schaper W, Drexler H, Limbourg FP. Evaluation of postnatal arteriogenesis and angiogenesis in a mouse model of hind-limb ischemia. Nature protocols. 2009;4(12):1737-46.

38. Skuli N, Majmundar AJ, Krock BL, Mesquita RC, Mathew LK, Quinn ZL, et al. Endothelial HIF-2a regulates murine pathological angiogenesis and revascularization processes. The Journal of clinical investigation. 2012;122(4):1427-43.

39. Zeoli A, Dentelli P, Rosso A, Togliatto G, Trombetta A, Damiano L, et al. Interleukin-3 promotes expansion of hemopoietic-derived CD45+ angiogenic cells and their arterial commitment via STAT5 activation. Blood. 2008;112(2):350-61.

40. Zhai L, Wu R, Han W, Zhang Y, Zhu D. miR-127 enhances myogenic cell differentiation by targeting S1PR3. Cell death \& disease. 2017;8(3):e2707.

41. Troy A, Cadwallader AB, Fedorov Y, Tyner K, Tanaka KK, Olwin BB. Coordination of satellite cell activation and self-renewal by Par-complex-dependent asymmetric activation of $p 38 a / \beta$ MAPK. Cell stem cell. 2012;11(4):541-53.

42. Criqui $\mathrm{MH}$, Aboyans V. Epidemiology of peripheral artery disease. Circulation research. 2015;116(9):1509-26.

43. Anderson JL, Halperin JL, Albert NM, Bozkurt B, Brindis RG, Curtis LH, et al. Management of patients with peripheral artery disease (compilation of 2005 and 2011 ACCF/AHA guideline recommendations): a report of the American College of Cardiology Foundation/American Heart Association Task Force on Practice Guidelines. Circulation. 2013;127(13):1425-43.

44. Tedesco FS, Dellavalle A, Diaz-Manera J, Messina G, Cossu G. Repairing skeletal muscle: regenerative potential of skeletal muscle stem cells. The Journal of clinical investigation. 2010;120(1):11-9.

45. Yu J, Dardik A. A Murine Model of Hind Limb Ischemia to Study Angiogenesis and Arteriogenesis. Methods in molecular biology (Clifton, NJ). 2018;1717:135-43.

46. Aref Z, de Vries MR, Quax PHA. Variations in Surgical Procedures for Inducing Hind Limb Ischemia in Mice and the Impact of These Variations on Neovascularization Assessment. International journal of molecular sciences. 2019;20(15).

47. Gao M, Zhao Z, Lv P, Li Y, Gao J, Zhang M, et al. Quantitative combination of natural anti-oxidants prevents metabolic syndrome by reducing oxidative stress. Redox biology. 2015;6:206-17.

48. Yang K, Chan CB. Proposed mechanisms of the effects of proanthocyanidins on glucose homeostasis. Nutrition reviews. 2017;75(8):642-57.

49. Tyagi A, Agarwal R, Agarwal C. Grape seed extract inhibits EGF-induced and constitutively active mitogenic signaling but activates JNK in human prostate carcinoma DU145 cells: possible role in antiproliferation and apoptosis. Oncogene. 2003;22(9):1302-16. 
50. Myburgh KH, Kruger MJ, Smith C. Accelerated skeletal muscle recovery after in vivo polyphenol administration. The Journal of nutritional biochemistry. 2012;23(9):1072-9.

51. Zammit PS, Golding JP, Nagata Y, Hudon V, Partridge TA, Beauchamp JR. Muscle satellite cells adopt divergent fates: a mechanism for self-renewal? The Journal of cell biology. 2004;166(3):347-57.

52. Zammit PS. Function of the myogenic regulatory factors Myf5, MyoD, Myogenin and MRF4 in skeletal muscle, satellite cells and regenerative myogenesis. Seminars in cell \& developmental biology. 2017;72:19-32.

53. Chargé SB, Rudnicki MA. Cellular and molecular regulation of muscle regeneration. Physiological reviews. 2004;84(1):209-38.

54. Sabourin LA, Girgis-Gabardo A, Seale P, Asakura A, Rudnicki MA. Reduced differentiation potential of primary MyoD-/- myogenic cells derived from adult skeletal muscle. The Journal of cell biology. 1999;144(4):631-43.

55. Vogiatzi G, Oikonomou E, Deftereos S, Siasos G, Tousoulis D. Peripheral artery disease: a micro-RNArelated condition? Current opinion in pharmacology. 2018;39:105-12.

56. Randrianarison-Huetz V, Papaefthymiou A, Herledan G, Noviello C, Faradova U, Collard L, et al. Srf controls satellite cell fusion through the maintenance of actin architecture. The Journal of cell biology. 2018;217(2):685-700.

57. Chen JF, Mandel EM, Thomson JM, Wu Q, Callis TE, Hammond SM, et al. The role of microRNA-1 and microRNA-133 in skeletal muscle proliferation and differentiation. Nature genetics. 2006;38(2):22833.

58. Veeranki S, Lominadze D, Tyagi SC. Hyperhomocysteinemia inhibits satellite cell regenerative capacity through p38 alpha/beta MAPK signaling. American journal of physiology Heart and circulatory physiology. 2015;309(2):H325-34.

59. Brien P, Pugazhendhi D, Woodhouse S, Oxley D, Pell JM. p38a MAPK regulates adult muscle stem cell fate by restricting progenitor proliferation during postnatal growth and repair. Stem cells (Dayton, Ohio). 2013;31(8):1597-610.

60. Kim HS, Asmis R. Mitogen-activated protein kinase phosphatase 1 (MKP-1) in macrophage biology and cardiovascular disease. A redox-regulated master controller of monocyte function and macrophage phenotype. Free radical biology \& medicine. 2017;109:75-83.

61. Gagan J, Dey BK, Layer R, Yan Z, Dutta A. Notch3 and Mef2c proteins are mutually antagonistic via Mkp1 protein and miR-1/206 microRNAs in differentiating myoblasts. The Journal of biological chemistry. 2012;287(48):40360-70.

\section{Figures}


A

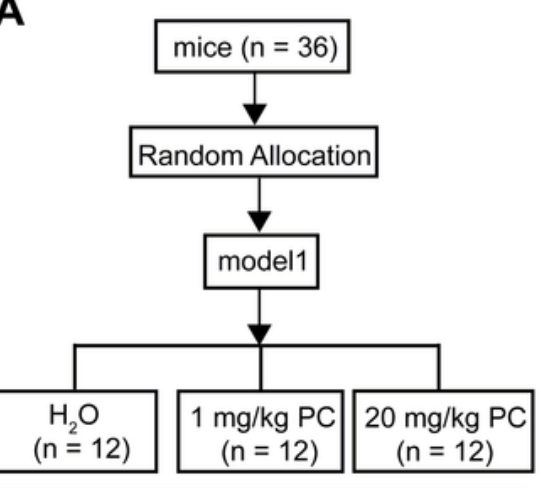

assessment

1. Movement Score

2.Muscle Regeneration

3. myogenic marker gene

4. Oxidation levels
B

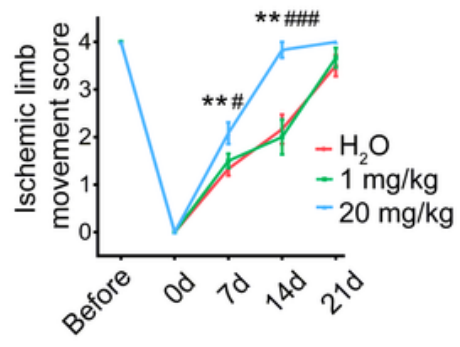

C

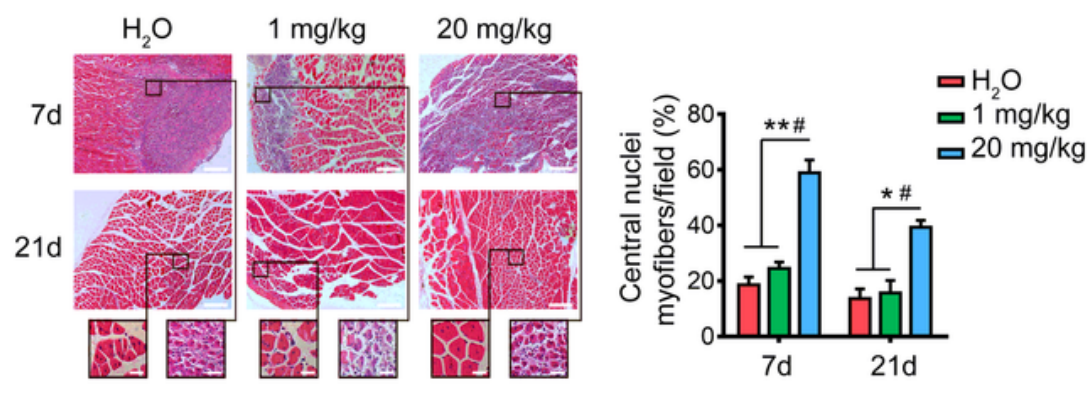

D

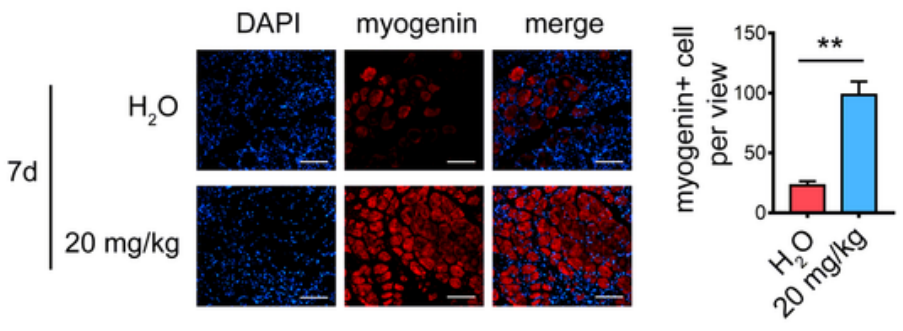

E
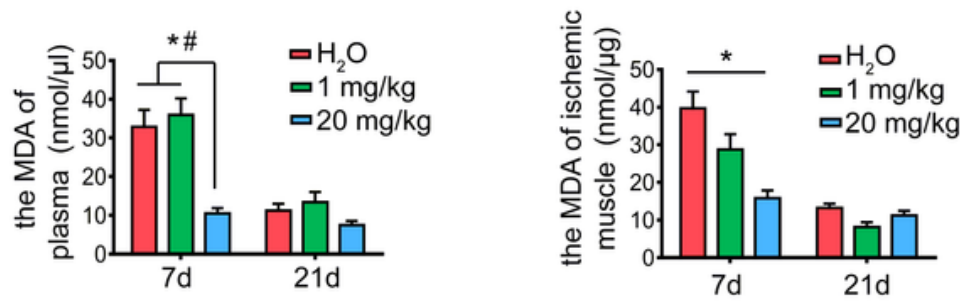

\section{Figure 1}

PC protected ischemic skeletal muscle by reducing the oxidative stress and promoting regeneration in unilateral limb ischemia mice. Unilateral limb ischemia mice were treated with H2O, $1 \mathrm{mg} / \mathrm{kg}$ PC and 20 $\mathrm{mg} / \mathrm{kg}$ PC from days 0 to 21: a mice unilateral limb ischemia with different treatments and assessments; b motor function scores of treatment mice were evaluated at before and days 0, 7, 14, and 21 postsurgery; c hematoxylin and eosin-stained with ischemic gastrocnemius from treatment mice at days 7 
and 21 (scale bar: $200 \mu \mathrm{m}$ ). The regenerating myofibers at higher magnification are showed in insets, characterized by central nucleus location (scale bar: $40 \mu \mathrm{m}$ ). Histogram represents the quantification of the percentage of regenerating fibers (central nuclei fibers/total muscle fibers of cross-sectional areas). $d$ Sections of ischemic gastrocnemius from saline or $20 \mathrm{mg} / \mathrm{kg}$ PC groups at day 7 post-surgery were stained for myogenin (red) and DAPI (blue) (scale bar: $100 \mu \mathrm{m}$ ). Histogram represents the quantification of myogenin+ cells per field in 5 random areas of different samples. e We measured the MDA levels of plasma and ischemic gastrocnemiusmice in treatment mice at days 7 and 21. Data were expressed as mean \pm SEM $(n=12) .20$ mg/kg PC vs H2O: *, $P<0.05 ; ~ * *, P<0.01 .20$ mg/kg PC vs 1 mg/kg PC: \#, $P<0.05$; $\# \#, P<0.01 ; \# \# \#, P<0.001$. 


\section{A}

Hypoxic-ischemic $24 \mathrm{~h}$

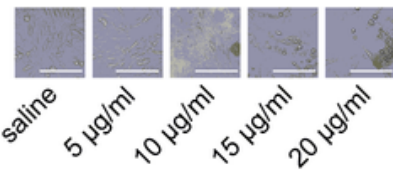

C

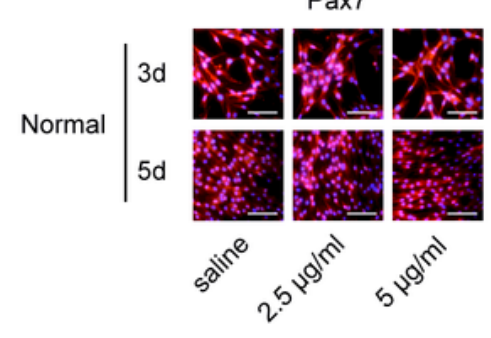

$\mathbf{E}$
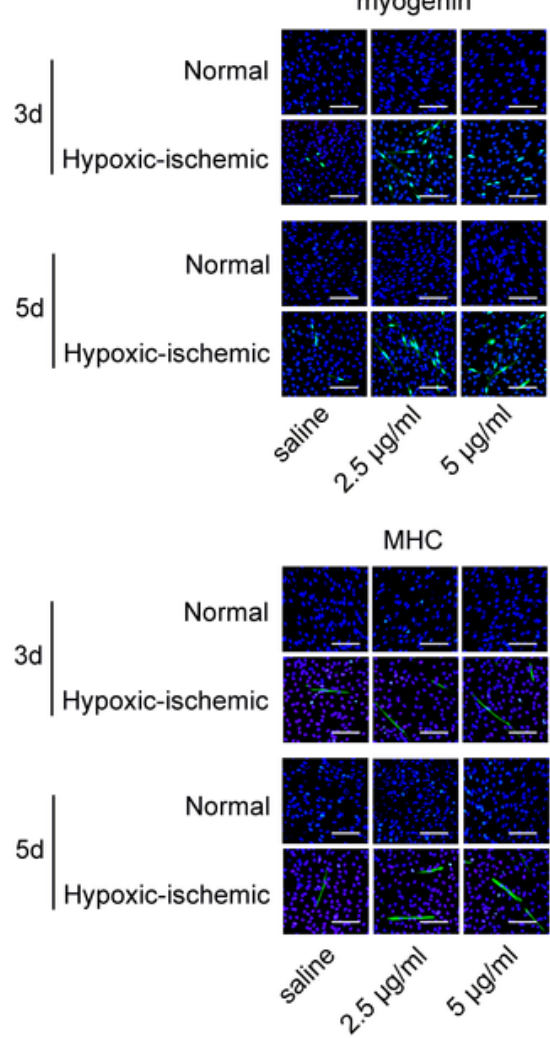

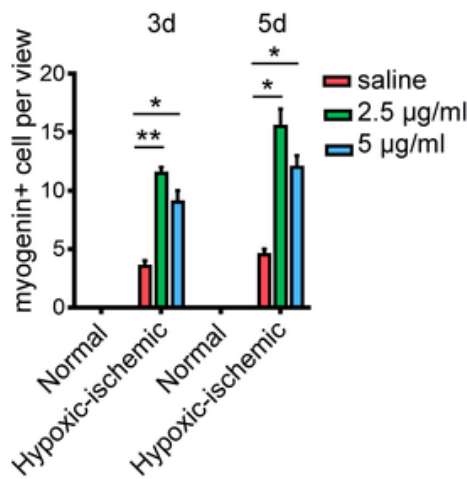

B
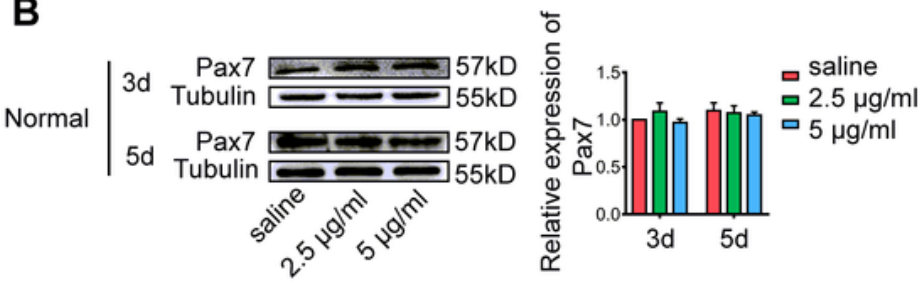

D
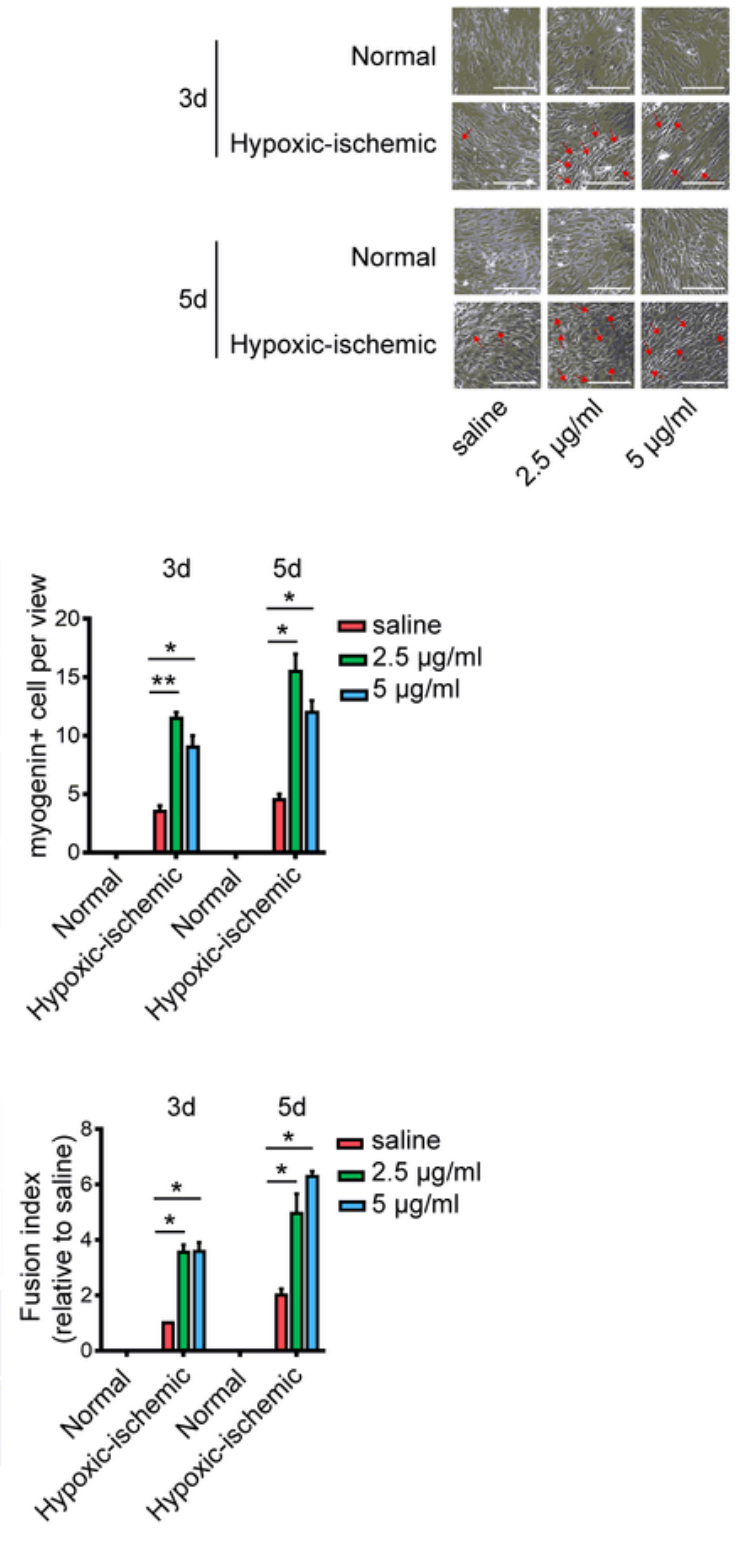

\section{Figure 2}

PC promoted HSKMSCs myogenic differentiation in vitro under hypoxic-ischemic condition. a Cells were incubated in media treated with saline or different concentrations PC $(5,10,15,20 \mu \mathrm{g} / \mathrm{ml})$ for $24 \mathrm{~h}$ under hypoxic-ischemic condition. HSKMSCs were treated with saline or PC (2.5 or $5 \mu \mathrm{g} / \mathrm{ml})$ for 3 and 5 days under normal condition, expression of Pax7 was determined using b Western blot and $\mathrm{c}$ immunofluorescence staining for Pax7 (red), and DAPI (blue) in HSKMSCs (scale bar: $100 \mu m)$. Then, 
cells were incubated in media treated with saline or PC $(2.5$ or $5 \mu \mathrm{g} / \mathrm{ml})$ for 3 and 5 days under normal or hypoxic-ischemic condition: $d$ myotubes formation were observed by microscope. Red arrows indicate myotubes (scale bar: $100 \mu \mathrm{m}$ ); e immunofluorescence staining for myogenin (green), MHC (green) and DAPI (blue) in HSKMSCs (scale bar: $100 \mu \mathrm{m}$ ). Histogram represents the quantification of the number of myogenin+ cells per field in 5 random areas of different samples of each group. Fusion indices were calculated based on $\mathrm{MHC}+$ cells presented in panel. Fusion index is counted as the percentage of total nuclei present in multinucleated myotubes. The protein expression levels were normalized to tubulin. Data were expressed as mean \pm SEM. * $P<0.05 ; * \star, P<0.01$ 

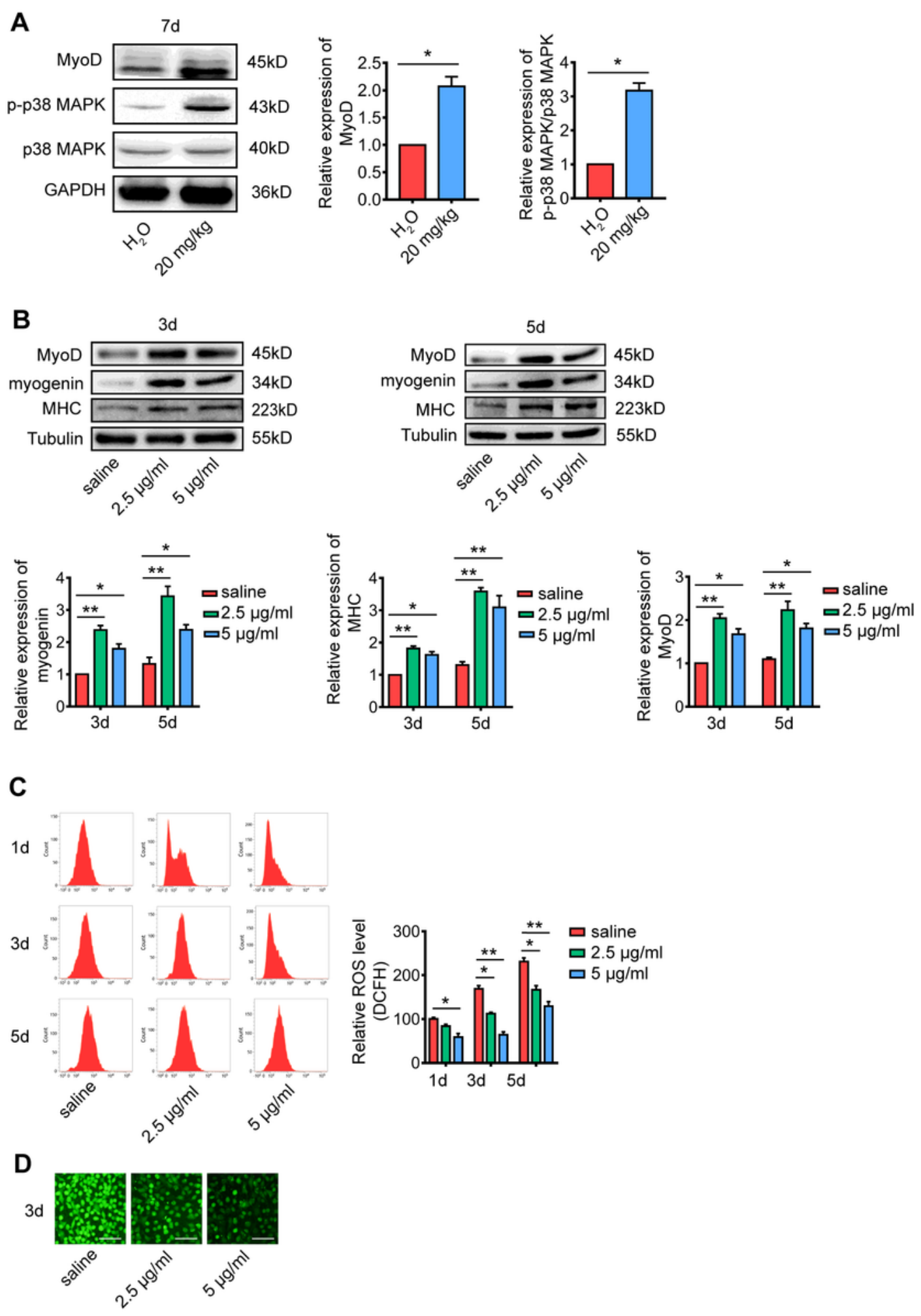

\section{Figure 3}

PC improved the expression of myogenic marker genes both in vivo and vitro. a After unilateral limb ischemia mice were treated with $20 \mathrm{mg} / \mathrm{kg}$ PC or $\mathrm{H} 2 \mathrm{O}$ for 7 days in vivo. Ischemic gastrocnemius was collected at day 7, expression of MyoD, p38-MAPK, p-p38-MAPK was determined using Western blot. b After HSKMSCs were treated with saline or PC $(2.5$ or $5 \mu \mathrm{g} / \mathrm{ml})$ for 3 and 5 days under hypoxic-ischemic condition in vitro, expression of MHC, MyoD, myogenin were determined using Western blot. c After 
HSKMSCs were treated with saline or PC $(2.5$ or $5 \mu \mathrm{g} / \mathrm{ml})$ for 1,3 and 5 days under hypoxic-ischemic condition, the ROS levels were determined using flow cytometry, and d laser scanning confocal microscope at day 3 (scale bar: $100 \mu \mathrm{m}$ ). All the relative protein levels of p-p38-MAPK expression were quantified as the ratio of the level of p-p38-MAPK to the p38-MAPK. The other protein expression levels were normalized to GAPDH or tubulin. Data were expressed as mean \pm SEM. * $P<0.05 ; * *, P<0.01$

A

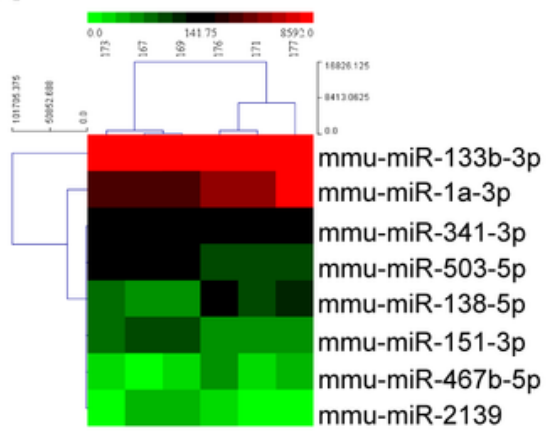

C

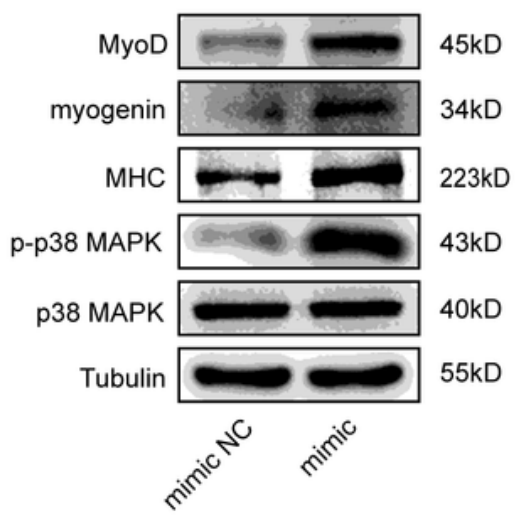

B
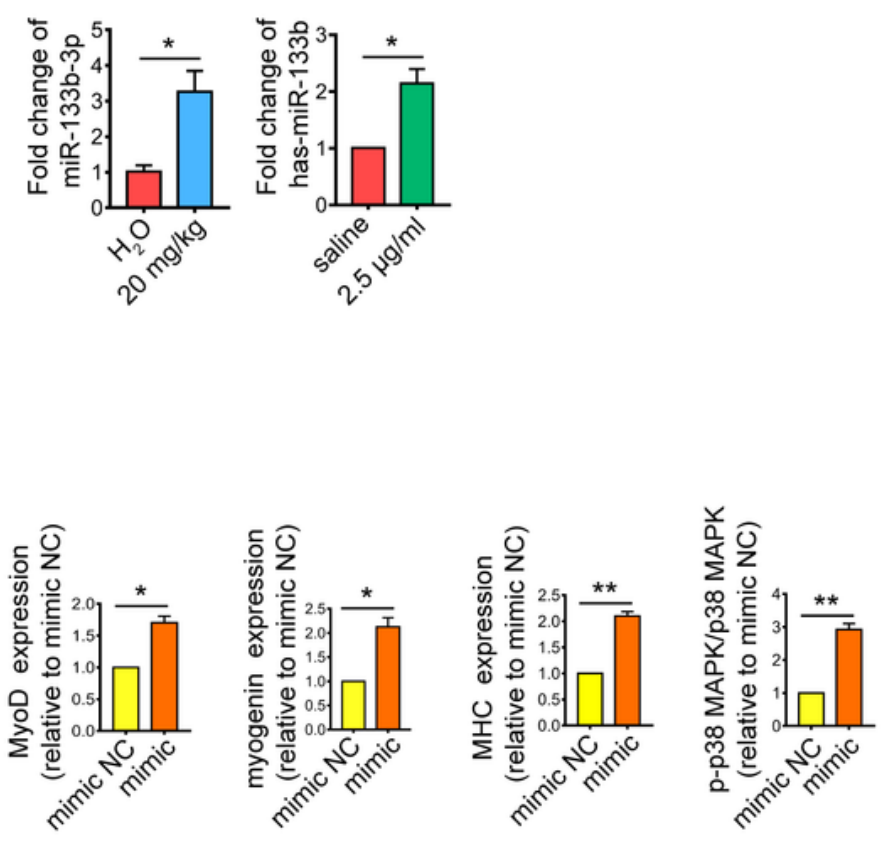

D
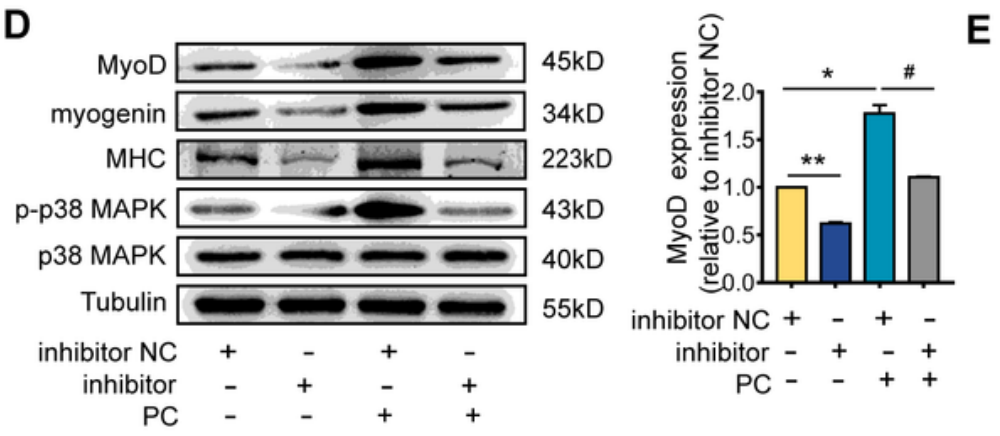

E
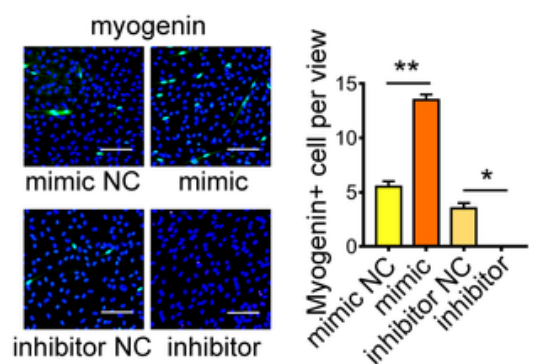

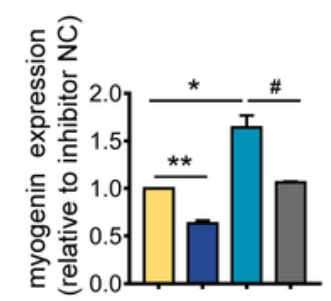

inhibitor $\mathrm{NC}+-+$ inhibitor -+-+ $\mathrm{PC}--++$

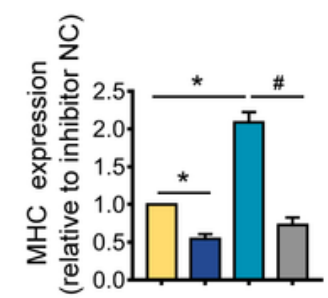

inhibitor $\mathrm{NC}+-+$ inhibitor - + -+ $\mathrm{PC}-{ }_{-}+$

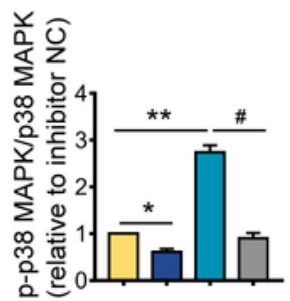

inhibitor NC + - + -

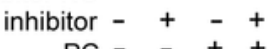

Figure 4 
PC induced the expression of miR-133b under hypoxic-ischemic condition to promote myogenic differentiation by activating p38-MAPK signal pathway. After unilateral limb mice treated with $20 \mathrm{mg} / \mathrm{kg}$ $\mathrm{PC}$ or $\mathrm{H} 2 \mathrm{O}$ for 7 days: a gastrocnemius was collected to investigate by miRNA profile. Heat map diagram is shown through clustering the differentially expressed miRNAs. Detailed methods and complete raw data level of the microarray results were deposited in the Gene Expression Omnibus (GEO, http://www.ncbi.nlm.nih.gov/geo/) and can be accessed through the accession number GSE146772. b miR-133b-3p expression of mice gastrocnemius was analyzed by RT-qPCR. While miR-133b expression of HSKMSCs was analyzed by RT-qPCR. miRNA levels were normalized to U6. After transfection with miR133b mimic NC, miR-133b mimic, miR-133b inhibitor NC, miR-133b inhibitor, then followed by hypoxicischemic treatment for 3 days: $c$, d expression of MHC, MyoD, myogenin, p38-MAPK, p-p38-MAPK were determined using Western blot and e immunofluorescence staining for myogenin (green) and DAPI (blue) in HSKMSCs were analysis and quantification was analyzed as mentioned above. All the relative protein levels of p-p38-MAPK expression were quantified as the ratio of the level of p-p38-MAPK to the p38MAPK. The other protein expression levels were normalized to tubulin. Data were expressed as mean \pm SEM. * $\mathrm{P}<0.05 ; * \star, \mathrm{P}<0.01 ; \#, \mathrm{P}<0.05$ 
A

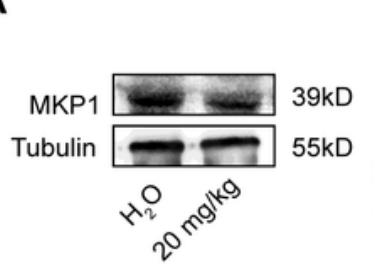

B

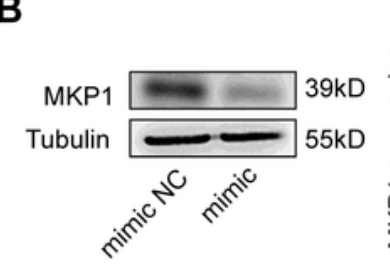

C
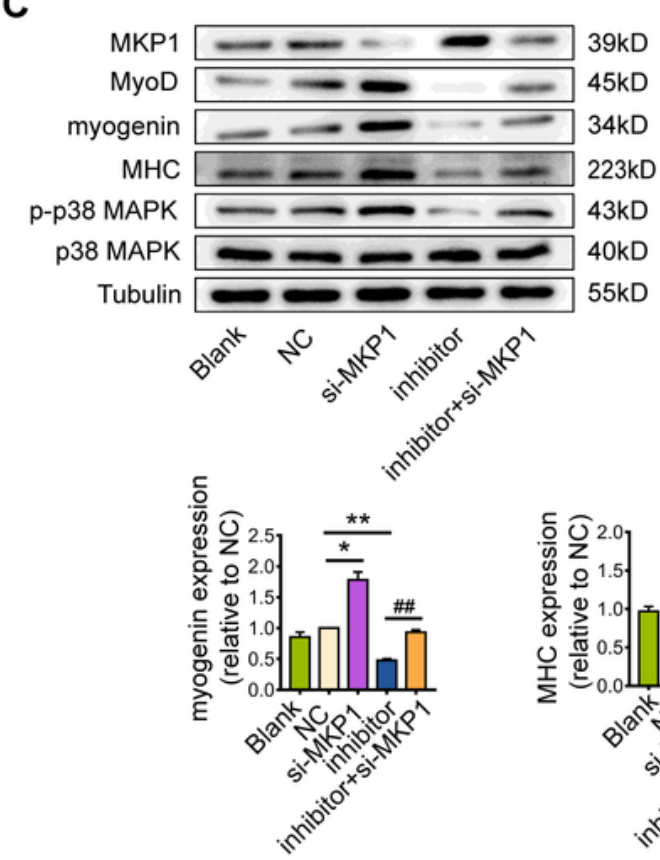

D

hsa-miR-133b

h-DUSP1-3UTR-wt h-DUSP1-3UTR-mu
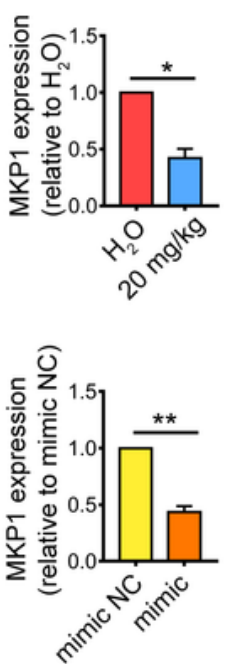
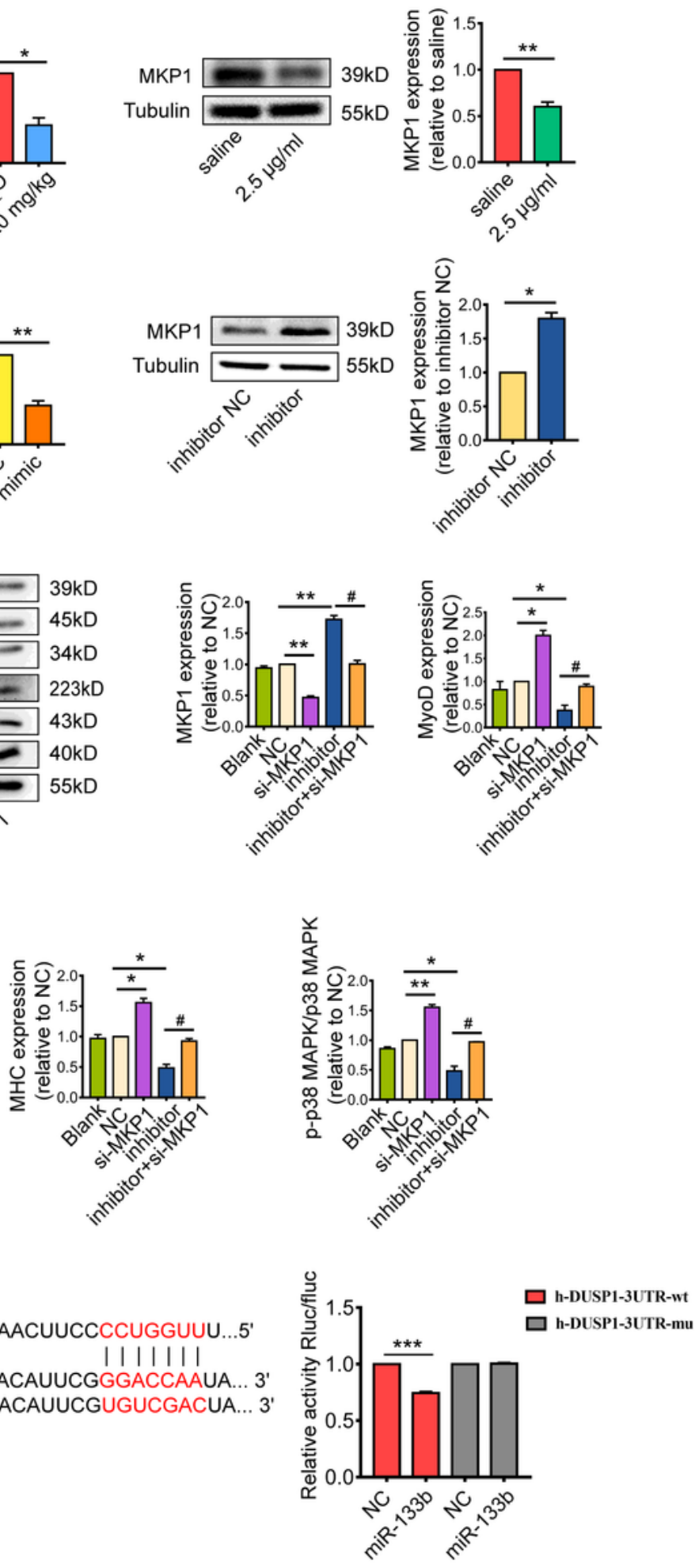

\section{Figure 5}

MiR-133b directly targets MKP1 and negatively regulated its expression. a expression of MKP1 in ischemic gastrocnemius treated as mentioned above was determined using Western blot. Expression of MKP1 in HSKMSCs treated as mentioned above was determined using Western blot. After transfection with miR-133b mimic NC, miR-133b mimic \miR-133b inhibitor NC, miR-133b inhibitor, or MKP1 siRNA, then followed by hypoxic-ischemic treatment for 3 days: b Expression of MKP1 and c Expression of MHC, 
MyoD, myogenin, MKP1, p38-MAPK, p-p38-MAPK in HSKMSCs were determined using Western blot. d Predicted binding sites of miR-133b within the MKP1 3'-UTR-wt and MKP1 3'-UTR-mu are shown. Relative activity of rluc/fluc was analyzed as mentioned above. All the relative protein levels of p-p38-MAPK expression were quantified as the ratio of the level of p-p38-MAPK to the p38-MAPK. The other protein expression levels were normalized to tubulin. Data were expressed as mean $\pm S E M .{ }^{*}, P<0.05 ; * *, P<0.01$; $\#, P<0.05 ; \# \#, P<0.01$

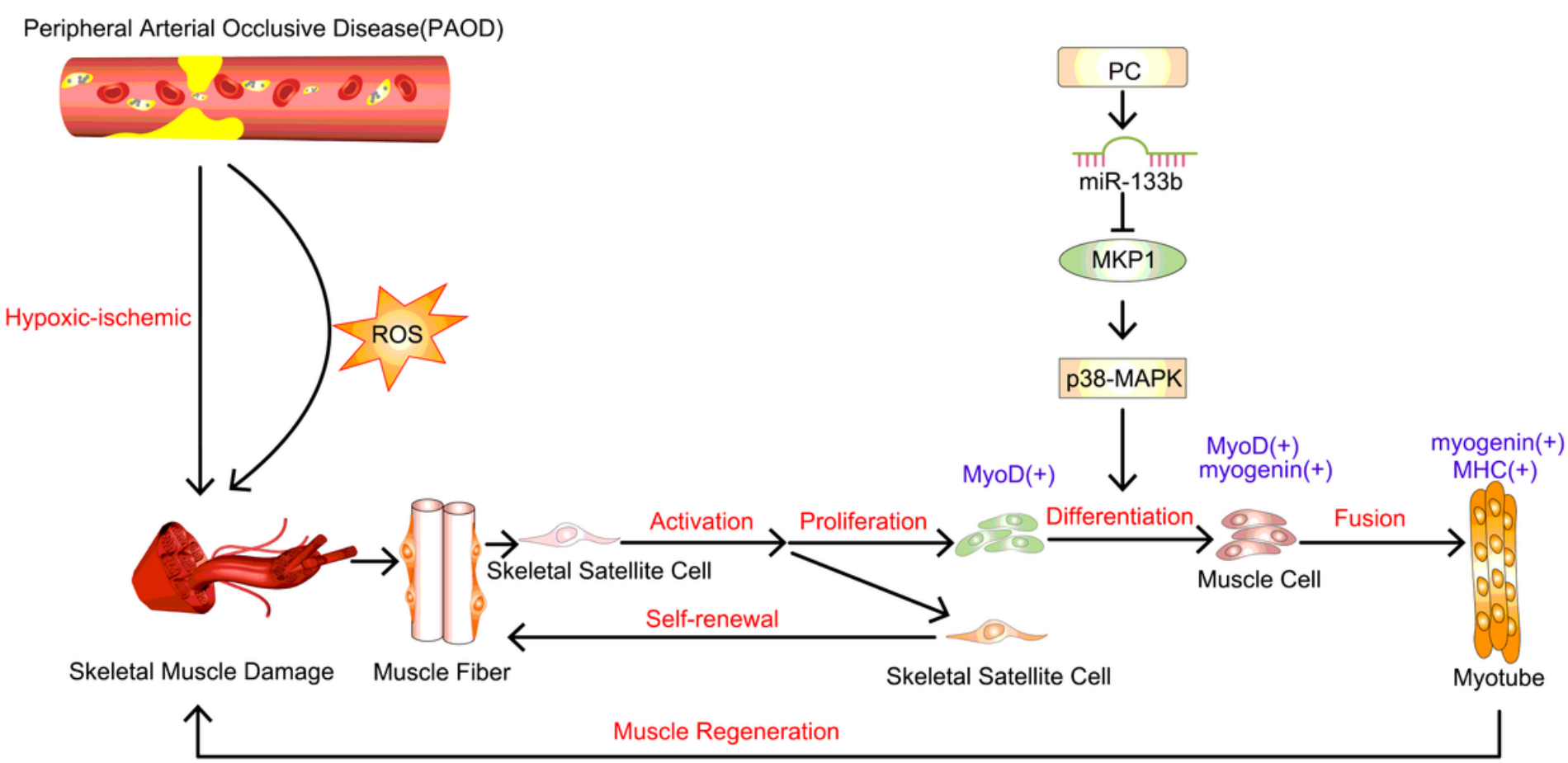

Figure 6

The mechanism of ischemic skeletal muscle regeneration promoted by PC.

\section{Supplementary Files}

This is a list of supplementary files associated with this preprint. Click to download.

- Additionalfile2SupplementaryFig2.tif

- Additionalfile2SupplementaryFig2.tif

- AdditionalfileSupplementaryFig1.tif

- AdditionalfileSupplementaryFig1.tif 